\title{
Commentary: Defining success in surgery
}

\author{
Daniel P. Raymond, MD
}

How does one determine the success of an operation? On the surface, this seems simple. First, what is the goal of the operation? Second, how do we measure that goal? Although this seems rather simplistic, the truth is that we, as surgeons, don't do it enough.

The treatment of pectus excavatum is an excellent example. What is the goal of surgery? Cosmetic improvement is one and not an easy one to measure. Physiologic improvement, now at least here we have some objective measurements such as pulmonary function testing and cardiopulmonary exercise testing to guide the way. So have those objective functional improvements been defined? The answer is "no." Into this fray enter de Loos and colleagues, ${ }^{1}$ who characterize the learning curve associated with adopting the Nuss procedure at a single institution. This program begins with a formal proctoring period of 10 cases, after which, they document that 3 separate surgeons are subsequently able to perform at a proficient level without the typical learning curve. Thus, they have provided guidance on the establishment of a new program in Nuss procedures. Notably, learning does occur during this process, as the authors comment on several changes in practice during this period to avoid complications, most commonly bar displacement. The authors choose to use the absence of complications as the measure of success, similar to the standards of our Societies, and modify their practices to avoid such events. They furthermore document this while keeping a pace up of roughly 1 procedure a month. This is not a trivial frequency of procedures, especially in the realm of adult pectus excavatum repair.

\footnotetext{
From Thoracic and Cardiovascular Surgery, Cleveland Clinic, Cleveland, Ohio. Disclosures: The author reported no conflicts of interest.

The Journal policy requires editors and reviewers to disclose conflicts of interest and to decline handling or reviewing manuscripts for which they may have a conflict of interest. The editors and reviewers of this article have no conflicts of interest.

Received for publication Dec 23, 2020; revisions received Dec 23, 2020; accepted for publication Dec 23, 2020; available ahead of print Jan 10, 2021.

Address for reprints: Daniel P. Raymond, MD, Thoracic and Cardiovascular Surgery, Cleveland Clinic, 9500 Euclid Ave, J4-1, Cleveland, OH 44195 (E-mail: Raymond3@ccf.org).

J Thorac Cardiovasc Surg 2022;163:839-40

0022-5223/\$36.00

Copyright (C) 2021 by The American Association for Thoracic Surgery

https://doi.org/10.1016/j.jtcvs.2020.12.122
}

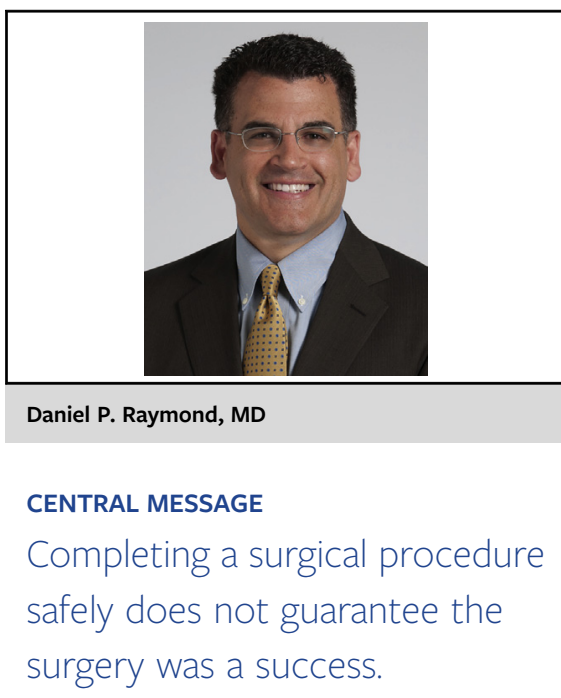

For many surgeries, due to the challenges of measuring the actual goal of the operation, we have sought surrogate measures, those being short-term outcomes after surgery, that are accessible, definable, and measurable. For cancer, rather than measure 5-year survival, the goal we are actually trying to achieve, we measure 30-day or 90-day survival. We further track rates of morbid events that can also be tallied and scored. This strategy, however, is coming under greater scrutiny as we demonstrate that short-term results and long-term goals are not always concordant. ${ }^{2}$ Moreover, we have to actually scrutinize what the long-term goals are. Is it length of life, length of life without disease, functional independence, patient quality of life measures, or a composite of such measures?

In the end, I believe as a Surgical Society, we have become complacent with respect to outcome measurement. The authors have demonstrated that they can safely implant stainless-steel bars into the chest with a low complication rate. Did they achieve a functional improvement or cosmetic improvement deemed worthwhile by the patient? I do not mean to single out the authors, as I daresay most thoracic surgeons cannot quote their disease-specific and stage-specific survival when counseling a patient regarding some of the most common cancer operations we perform. In the realm of pectus excavatum repair, indications remain subjective with a crude objective measure, the Haller index, to guide us. Given our access to modern physiologic testing, why have we not defined parameters that would identify the appropriate patients for surgery with the ability to prognosticate regarding result? In cancer, we have clinical staging and functional testing to guide us in our decision-making; for pectus, we have a ratio of width to height of the thorax. 
Just as a surgeon should be able to quote a patient their 5 -year survival rate for cancer surgery, a surgeon should be able to quote patients a percent functional improvement or patient satisfaction score following pectus excavatum repair. Until that point, none of us will know if the surgery was a success.

\section{References}

1. de Loos ER, Daemen JHT, Penning AJ, Heuts S, Maessn JG, Hulsewé KWE, et al. Minimally invasive repair of pectus excavatum by the Nuss procedure: the learning curve. J Thorac Cardiovasc Surg. 2022;163:828-37.e4.

2. Fernandez FG, Kosinski AS, Tong BC, Furnary AP, Feng L, Onaitis MW, et al. Lack of correlation between short- and long-term performance after lung cancer surgery. J Thorac Cardiovasc Surg. 2019;157:1633-43. 